EESTI NSV TEADUSTE AKADEEMIA TOIMETISED. XVII KÖIDE
KEEMIA * GEOLOOGIA. 1968, Nr. 4

ИЗВЕСТИЯ АКАДЕМИИ НАУК ЭСТОНСКОИ ССР. ТОМ ХVII Химия * ГЕОЛогия. 1968, № 4

\title{
БРАХИОПОДЫ РОДОВ CREMNORTHIS И PAURORTHIS ИЗ СРЕДНЕГО ОРДОВИКА ЭСТОНИИ
}

Описываемые здесь два новых вида Cremnorthis uhakuana и Paurorthis savalaensis являются первыми находками представителей родов Cremnorthis и Paurorthis из среднего ордовика Эстонии. Они имеют определенное значение не только для целей местной стратиграфии, но и для уточнения вопросов общего распространения этих родов.

Род Cremnorthis установлен в лонгвилльском горизонте (в группе Гелли Грин) Англии, в регионе Бала (Williams, 1963) и представлен только одним сравнительно редко встречающимся видом Cremnorthis parva. В Прибалтике этот род довольно широко распространен по вертикали: в Әстонин - от ласнамягиского $\left(\mathrm{C}_{\mathrm{I}} \mathrm{b}\right)$ горизонта до сандуского $\left(\mathrm{D}_{\mathrm{III}}\right)$, в Литве * - в нерасчлененном комплексе идавере-санду (Пашкевичюс, 1959). Кроме того, род Cremnorthis встречается в нижней части среднего ордовика Московской синеклизы. Значительно более раннее появление и широкое вертикальное и площадное распространение этого рода в северо-западной части Русской платформы позволяет предположить, что он переместился в Англию из Балтийского бассейна. О такой возможности говорит и общее увеличение, по сравнениюо с нижележащими горизонтами, балтоскандийских элементов в фауне брахиопод лонгвилльского горизонта, особенно в отложениях группы Гелли Грин (Williams, 1963).

Род Paurorthis был до сих пор известен в Балтоскандии только из нижнего ордовика: из горизонтов от латорпского ( $\left.\mathrm{B}_{\mathrm{I}}\right)$ до кундаского $\left(\mathrm{B}_{\mathrm{III}}\right)$ в Эстонии (Алихова, 1953; Рубель, 1961), из латорпского (BI) и волховского $\left(\mathrm{B}_{\mathrm{II}}\right)$ - в Литве (Пашкевичюс, 1959) и из экспанзусовых слоев $(3 \mathrm{c} \beta)$ в Норвегии (Öрik, 1939). В Северной Америке этот род более чем с десятью видами известен только из среднего ордовика Аппалачской геосинклинали (Cooper, 1956). Первые находки рода Paurorthis из среднего ордовика за пределами Аппалачской геосинклинали были сделаны в Европе в Шотландии (из известняка Стинчар и нижних мергелей Ардуэлл; Williams, 1962) и Богемии (формация Дроботива; Havliček and Vanek, 1966). K ним добавляется теперь описанный ниже вид Paurorthis savalaensis из среднего ордовика Әстонии.

Bce описанные в статье экземпляры хранятся в Геологическом музее Института геологии АН ӘССР в Таллине.

* Имеется в внду материал, обозначенный Ю. Пашкевичюсом как Paurorthis (?) prenaica. Автор имел возможность бегло ознакомиться с этим материалом в Вильнюсском университете. 
О П ИСАН И В ИДОВ

\section{НАДСЕМЕИСТВО ORTНAСЕA WOODWARD, 1852}

\section{CEMEЙTВO CREMNORTHIDAE WILLIAMS, 1963}

\section{Род Cremnorthis Williams, 1963}

\section{Cremnorthis uhakuana n. sp.}

Табл. I, фиг. 1-13; табл. II, фиг. 10-12

Голотип. Целый экземпляр $\mathrm{Br} 4114$, табл. I, фиг. 1-5. Ухакуский горизонт $\left(\mathrm{C}_{\mathrm{I}} \mathrm{c}\right)$, Северная Әстония, обн. Кыргекаллас у р. Пуртсе.

Ди агноз. Вид рода Cremnorthis с небольшой раковиной округленно-треугольного до трапециевидного очертания. Число ребрышек на расстоянии 2 мм от макушки в 1 м.м 6-8, а общее их число достигает 45 .

О п и с а н и е. Раковина небольших размеров, двояковыпуклая, с более выпуклой брюшной створкой. Очертание округленно-треугольное до трапециевидного. Замочные углы прямые или немного заостренные. Передняя комиссура сулькатная. Замочная линия прямая, соотвегствует наибольшей ширине раковины.

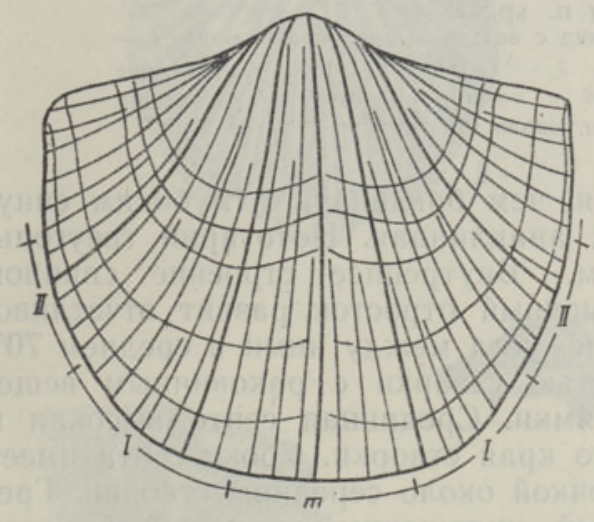

A

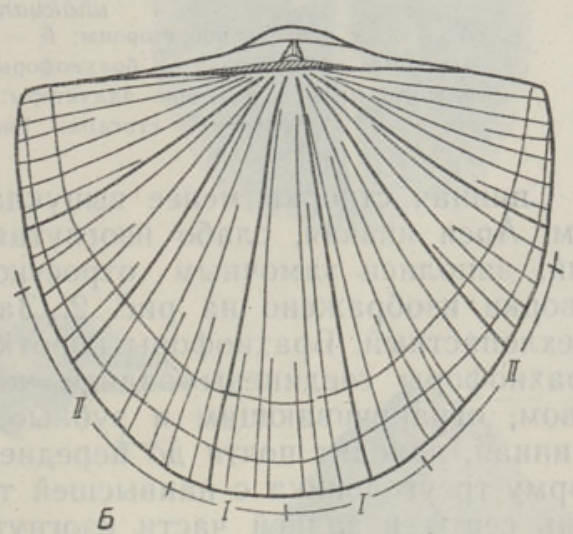

6

Рис. 1. Схема скульптуры Cremnorthis uhakuana n. sp.:

Широкие линии - более толстые первнғные ребрышки; $A$ - брюшная створка; $m-$ срединный сектор; I - первый боковой сектор, ребрышки отщепляются главным образом в боковую сторону; II -- второй боковой сектор. ребрышки отщепляктся в обе стороны от первичного, 5 - спннная створка; I и II - секторы, образующие соответственно синус и более выпуклую часть створки, ребрышки в первом секторе отщепляются главным образом в сторону средннной линин, во втором - в обе сторояы от первичного. Увел. около 15X

Скульптура состоит из многочисленных тонких ребрышек, угловатых в поперечном сечении. Число ребрышек вдоль срединной линии на расстоянии 2 мм от макушки $6-8$ в 1 мм. Общее число ребрышек по краям раковины доходит до 45, из. которых 8-10 начинаются от макушки (первичные). 5-6 первичных ребрышек более толстые. Увеличение ребрышек в числе происходит путем многократного отщепления (рис. 1). Линии нарастания выражены хорошо. 
Брюшная створка выпуклая, с килеобразной средней частью. Боковые части створки, в частности около замочных углов, уплсщены. Макушка маленькая, загнутая. Арея невысокая, вогнутая, апсаклинная. Дельтирий треугольный, открытый. Зубы массивные, короткие; утолщения их окаймляют глубокую дельтириальную полость. Дно последней по отношению к поверхности створки несколько приподнято в виде низкой платформы. В макушечной части дельтириальной полости маленькое утолщение. Дно створки гладкое и только по краям ребристое.
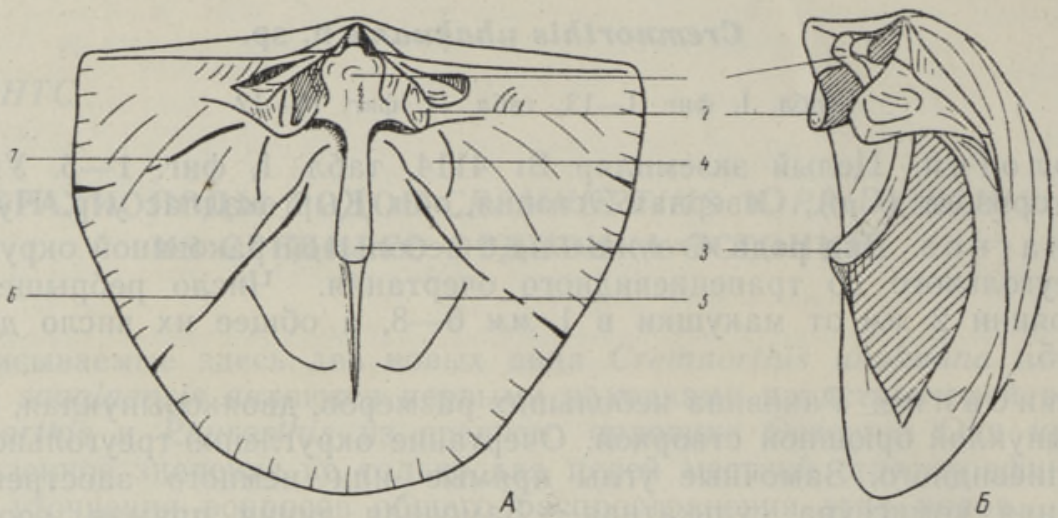

Рис. 2. Схемы внутреннего строения спинной створки Cremnorthis uhakuana n. sp.:

$A$ - вид с вентральной стороны; $B$ - внд с вентро-латеральной стороны. 1 замочный отросток; 2 - брахиофоры: 3 - срединная септа; 4 - задние аддукторы; 5 - передние аддукторы: 6 - vascula antemyaria, 7 - vascula cruraila. Увел, около $15 \times$.

Спинная створка менее выпуклая, чем брюшная, с глубоким синусом. Арея низкая, слабо изогнутая, анаклинная. Нототирий треугольный, заполнен замочным отростком. Внутреннее строение спинной створки изображено на рис. 2. Замочный отросток развит отчетливо, трехлопастный. Брахиофоры короткие, угол между ними в среднем $70^{\circ}$. Брахиофоры соединены задней частью створки с раковинным веществом, ограничивающим и зубные ямки. Срединная септа высокая и длинная, доходит почти до переднего края створки. Сбоку септа имеет форму треугольника с наивысшей точкой около середины створки. Гребень септы в задней части изогнутый, уплощенный, в передней части почти прямой, тонкий. Аддукторное поле овальное; передние аддукторы длинные, доходят в середине до передней части кардиналия. Задние аддукторы маленькие, расположены постеролаุтерально от передних.

\section{ТАБЛНЦА I}

Фиг, 1-5. Cremnorthis uhakuana n. sp. Голотип, целый экземпляр $\mathrm{Br} 4114$, вид со стороны брюшной и спинной створок, сбоку, спереди и сзади. Обн. Кыргекаллас (р. Пуртсе), С С. Увел. Х 10.

Фиг. 6-9. Cremnorthis uhakuana n. sp. Спинная створка $\mathrm{Br} 4118$, внешний вид, внутреннее строение, вид сзади и с вентро-латеральной стороны. Скв. Ныва, гл. 246,75 м, $\mathrm{C}_{\mathrm{II}}$. Увел. $\times 10$.

Фиг. 10. Cremnorthis uhakuana n. sp. Спинная створка $\mathrm{Br} 4134$, внутреннее строение. Обн. Кыргекаллас (р. Пуртсе), С $\mathrm{C}_{\mathrm{c}}$. Увел. Х 16.

Фиг. 11-13. Cremnorthis uhakuana n. sp. Целый экземпляр $\mathrm{Br} 4117$, вид со стороны

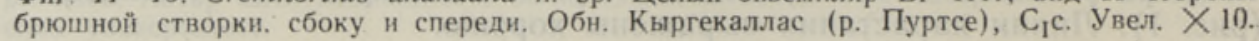


ТАБЛИЦА I
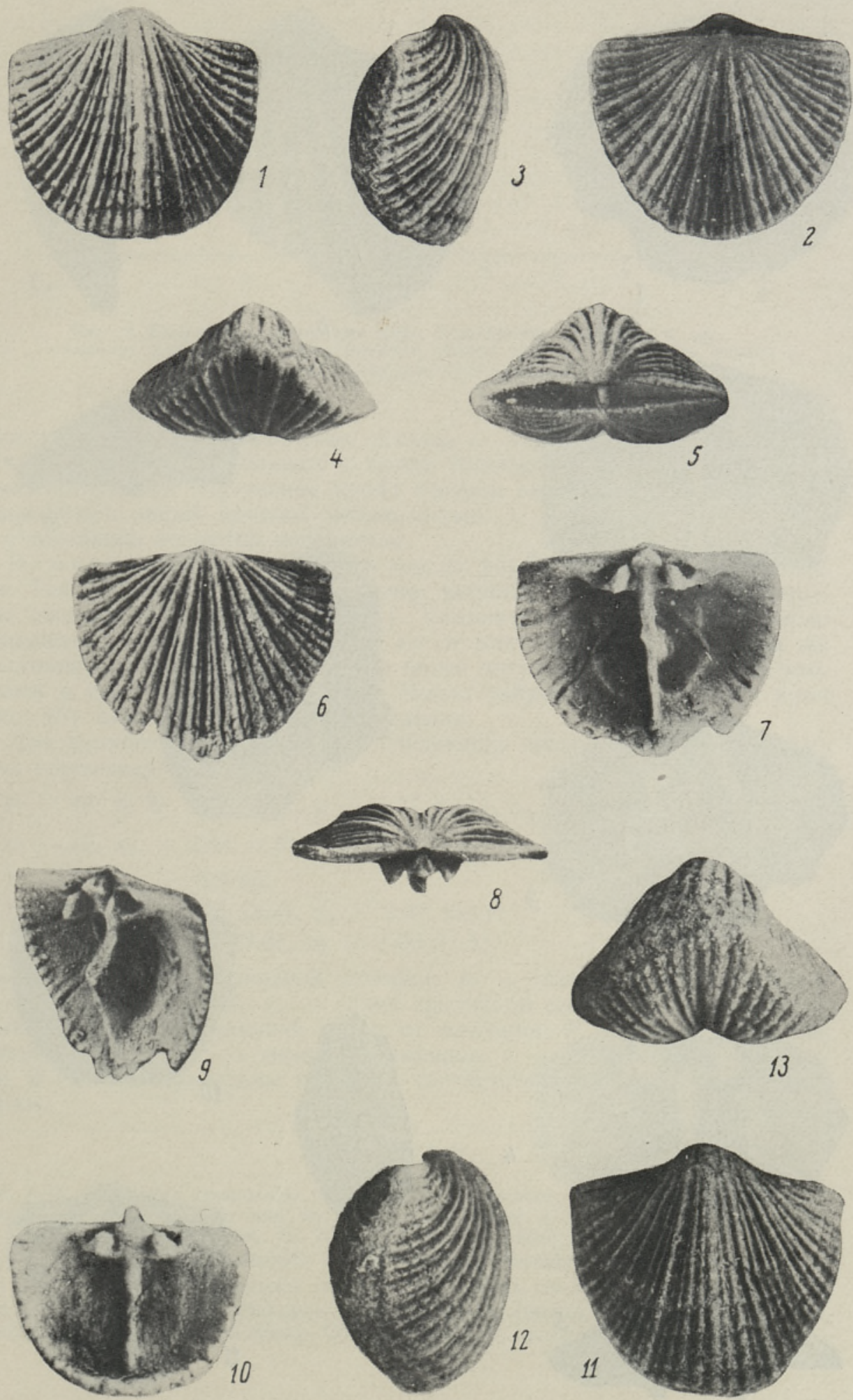
ТАБЛИЦА II
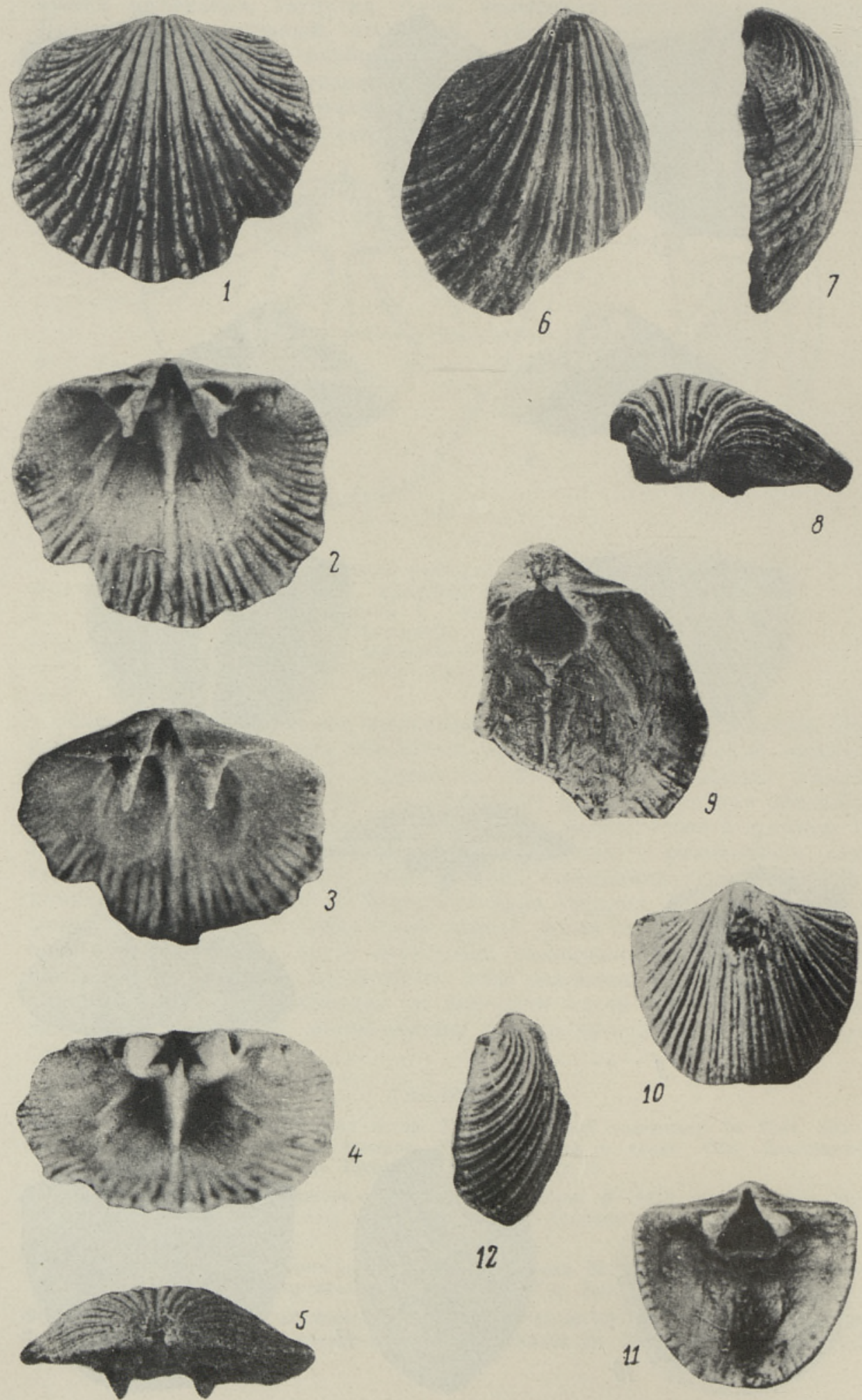

4

12

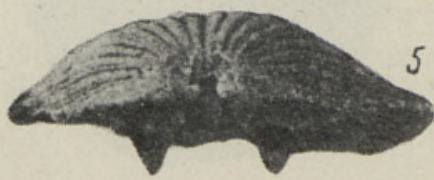



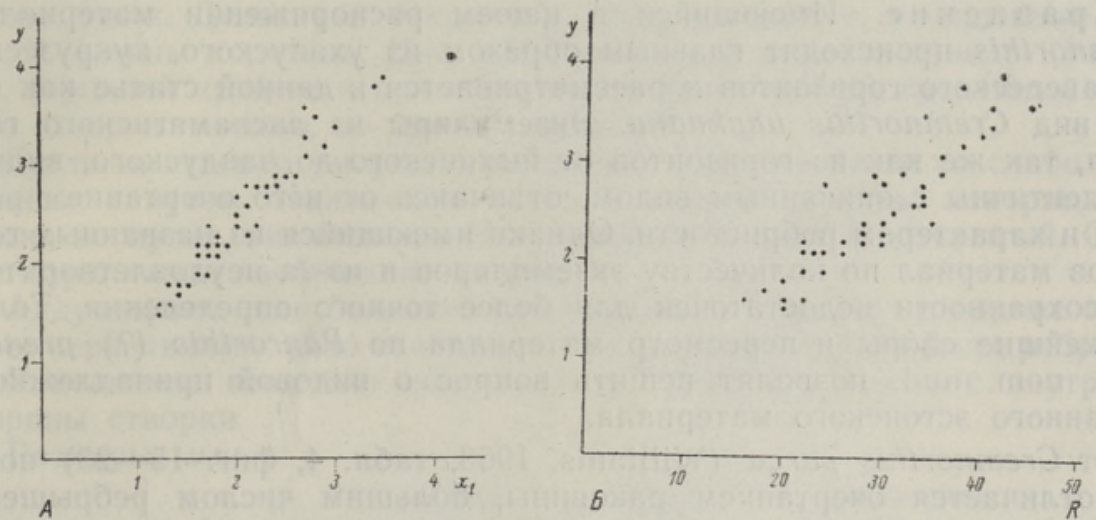

Рис. 3. Возрастные изменения вида Cremnorthis uhakuana n. sp.

$A$ - отношения ширины $(y)$ к длине брюшной створки $\left(x_{1}\right) ; \quad b-$ отношения ширины $\kappa$ числу ребрышек у переднего края раковины $(R)$.

Иногда различимы васкулярные сосуды — vascula anternyaria и vascula cruralia. Они совпадают с более толстыми первичными ребрышками, которые на внутренних краях створки выражены более четко по сравнению с общей краевой ребристостью.

Раковинное вещество непористое.

И з мен ч и вость. Описанный вид по форме раковины мало изменчив. Так, различные размеры (длина, ширина, толщина) имеют высокую степень корреляции (рис. $3 A$ ). Сравнительно постоянно и число ребрышек в 1 мм на расстоянии 2 мм от макушки (6-8). На этом же расстоянии от макушки начинается более интенсивное отщепление ребрышек в средней части раковины. Число ребрышек у переднего края (рис. $3 Б$ ) варьирует в бо́льших пределах.

Для данного вида характерны следующие средние величины (в мм) и их соотношения:

$$
\begin{aligned}
& n-48 ; x_{1}-2,07(4,2), y-2,47(4,1), r_{x_{1} y}-0,9933 \\
& n-55, x_{2}-2,00(4,0), r_{x_{2}}-0,9496 ; \\
& n-50, r_{R y}-0,8766 ; \\
& n-11, x_{2}-2,50(3,2), v_{1}-2,09(3,1) ; \\
& n-5, v_{1}-2,25(2,6), v_{2}-1,08(1,5) .
\end{aligned}
$$

Здесь $x_{1}$ - длина брюшной створки; $x_{2}$ - длина спинной створки; $y$ - ширина раковины; $v_{1}$ - длина срединной септы; $v_{2}$ - расстояние наивысшей точки срединной септы от макушки; $R$ - число ребрышек у переднего края; $n$ - число экземпляров; $r$ - коэффициент корреляции. В скобках приведены значения, соответствующие наибольшим размерам.

\section{ТАБЛИЦА ІІ}

Фиг. 1-5. Paurorthis savalaensis n. sp. Голотип, спинная створка $\mathrm{Br} 4122$, внешний вид, внутреннее строение, вид на кардиналий сзади и спереди, вид сзади. Скв. Савала, гл. 25,6-25,8 м, С СГ. Увел. Х9.

Фиг. 6-9. Paurorthis savalaensis п. sp. Брюшная створка $\mathrm{Br} 4123$, внешний вид. вид сбоку, вид сзади, внутреннее строение. Скв. Ныва, гл. 247,6 м. С Фиг. 10-12. Cremnorthis uhakuana n. sp. Брюшная створка $\mathrm{Br} 4115$, внешний вид, внутреннее строение, вид сбоку. Обн. Кыргекаллас (р. Пуртсе), С 
С равнение. Имеющийся в нашем распоряжении материал по Cremnorthis происходит главным образом из ухакуского, кукрузеского и идавереского горизонтов и рассматривается в данной статье как единый вид Cremnorthis uhakuana. Экземпляры из ласнамягиского горизонта, так же как из горизонтов от йыхвиского до оандуского, видимо, не идентичны с описанным видом, отличаясь от него очертанием раковины и характером ребристости. Однако имеющийся из названных горизонтов материал по количеству экземпляров и из-за неудовлетворительной сохранности недостаточен для более точного определения. Только дальнейшие сборы и пересмотр материала по Paurorthis (?) prenaica Pašk. nom. nud. позволят решить вопрос о видовой принадлежности названного эстонского материала.

От Cremnorthis parva (Williams, 1963, табл. 4, фиг. 15-23) новый вид отличается очертанием раковины, бо́льшим числом ребрышек и более расходящимися васкулярными сосудами спинной створки.

$\mathrm{P}$ аспространени е. Ухакуский $\left(\mathrm{C}_{\mathrm{I}} \mathrm{c}\right)$, кукрузеский $\left(\mathrm{C}_{\mathrm{II}}\right)$ и идавереский $\left(\mathrm{C}_{\mathrm{III}}\right)$ горизонты Северной Прибалтики.

М а те р и а л. С с: р. Ухаку -1 цел. экз., 6 бр. ств.; р. Пуртсе (обн. Кыргекаллас) - ок. 40 цел. экз., 2 бр. ств., 1 сп. ств.; Таллин - 1 цел. экз., 4 бр. ств., 4 сп. ств.; обн. Хийесоо - 1 цел. экз.; скв. Савала, гл. $39,98-40,03 \mu-1$ бр. ств.; $\mathrm{C}_{\mathrm{II}}$ : скв. Савала, гл. $18,80-18,84 \mu-$ 1 сп. ств.; скв. Ныва, гл. 46,75 м-1 цел. экз., 2 бр. ств., 4 сп. ств.; 47,0 $м-1$ цел. экз.; Убья - 1 сп. ств.; $\mathrm{C}_{\mathrm{III}}$ : скв. Лаэва, гл. 245,85 $\mu-$ 1 цел. экз., 247,8 $м-1$ сп. ств.; скв. Каагвере, гл. 286,4 $м-1$ цел. экз., 287,8-287,9 м- 1 цел. экз., 287,95-288,1 м-1 цел. экз., 3 бр. ств., 2 сп. ств.

\section{НАДСЕМЕИСТВО ЕNTELETACEA WAAGEN, 1884}

\section{CEMEИСТВО PAURORTHIDAE ÖPIK, 1933}

\section{Род Paurorthis Schuchert \& Cooper, 1931 \\ Paurorthis savalaensis n. sp.}

Табл. II, фнг. $1-9$

Г олоти п. Спинная створка $\mathrm{Br} 4122$, табл. II, фиг. $1-5$. Кукрузеский горизонт $\left(\mathrm{C}_{\mathrm{II}}\right)$, Северная Әстония, скв. Савала, гл. 25,6-25,8 м.

Д и агноз. Вид рода Paurorthis средних размеров, с относительно хорошо выраженным килеобразным замочным отростком и большим сердцевидным аддукторным полем. Число ребрышек в 1 мм у переднего края $4-5$.

Описание. Раковина средних для рода размеров, двояковыпуклая. Очертание раковины округлое, замочная линия прямая, замочные углы округленные. Наибольшая ширина раковины приурочена к ее средней части.

Ребрышки тонкие, собранные в пучки, поперечное сечение их угловатое. По краям в 1 мм насчитывается 4-5 ребрышек; общее их число 50 , из них 14 или 15 первичных. Увеличение их числа происходит путем расщепления. На гребнях ребрышек (в основном первичных) крупные экзопоры.

Брюшная створка выпуклая, с наивысшей точкой примерно в середине. Макушка маленькая, загнутая. Арея низкая, слабо вогнутая, 
апсаклинная. Дельтирий открытый. Зубы массивные, утолщенные. Зубные пластины короткие. Дно дельтириальной полости в виде плагформы, передний край ее непрямой и переходит в тонкую срединную септу. Дно створки гладкое, по краям ребристое.

Спинная створка умеренно выпуклая, в задней части со слабо выраженным синусом. Наивысшая точка в задней половине створки. Арея слегка вогнутая, анаклинная. Нототирий треугольный, открытый. Строение кардиналия изображено на рис. 4.

Аддукторное поле большое, сердцевидное. Передние и задние аддукторы неразличимы. Дно створки почти до аддукторного поля ребристое.

Раковинное вещество пористое, поры хорошо видны с внутренней стороны створки.

Размеры, мм:

$\begin{array}{cccc} & \text { Длина } & \text { Ширина } & \text { Длина ареи } \\ \mathrm{Br} 4122 & 4,5 & 5,1 & 3,5 \\ \mathrm{Br} 4123 & 8,9 & \simeq 10 & -\end{array}$

С равнение. Новый вид отличается от нижнеордовикских представителей рода Paurorthis (Рубель, 1961, с. 189-198) относительно хорошо развитым замочным отростком, бо́льшими размерами аддукторного поля и более тонкими ребрышками. $\mathrm{y}$ описанного вида в 1 мм у переднего края 4 -5 ребрышек, у нижнеордовикских вндов, кроме $P$. minima, $1-3$ ребрышка. От известных среднеордовикских вндов (Сооper, 1956 , с. $957-964 ;$ Williams, 1962 , с. $140-142$ ) новый вид отличается очертанием раковины и характером ребристости, а также очертанием мускульных полей и наличием тонкой срединной септы на брюшной створке. Из среднеордовикских видов наибольшее сходство имеют Paurorthis fasci-

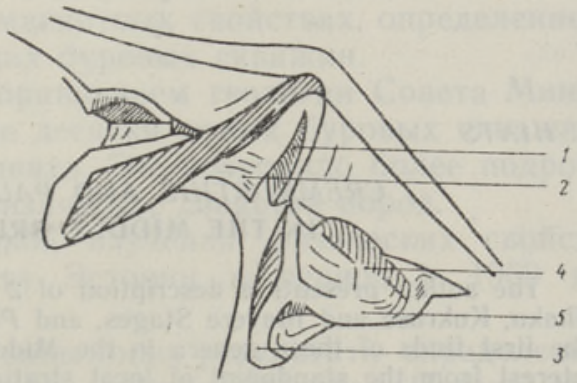

Рис. 4. Схема строения кардиналия Paurorthis savalaensis n. sp.: 1 - замочный отросток: 2 - нототирнальная платформа; 3 - брахиофор; 4 - зубная ямка; 5 - раковинное вещсство, ограничивающее зубные ямки и соединяющее брахиофоры с задней частью створки. fera (Cooper, 1956, c. 966, 967) и

Paurorthis sp. (Williams, 1962, c. 141). От первого наш вид отличается меньшим общим числом ребрышек и более короткой ареей, от второго более ясно выраженными пучками ребрышек и очертанием мускульного поля брюшной створки.

Р асп ростран ение. Кукрузеский горизонт $\left(\mathrm{C}_{\mathrm{II}}\right)$, Эстония.

М а т е р и ал. Скв. Савала, гл. 25,6-25,8 $м-1$ сп. ств.; скв. Ныва, гл. $247,6 \mu-1$ бр. ств.

\section{Л ИТ Е РАТ У Р А}

А лих хо в Т Т. Н. 1953. Руководящая фауна брахнопод ордовикских отложений северозападной части Русской платформы. Тр. ВСЕГЕИ. М.

П ашкевич юс И. Ю. 1959. Ордовик. В кн.: Краткий очерк геологии Литовской ССР. Вильнюс.

Р у бел ь М. П. 1961. Брахиоподы надсемейств Orthacea, Dalmanellacea и Syntrophiaсеа из нижнего ордовика Пгибалтики. Тр. Ин-та геол. АН ЭССР, VI.

C o oper G. A. 1956. Chazyan and related Brachiopods. Smiths. Misc. Coll., vol. 127. 
H a v liček V. and V a nek J. 1966. The biostratigraphy of the Ordovician of Bohemia. Sborník Geologických Véd. Paleontologie, sv. 8.

Ö ik A. 1939. Brachiopoden und Ostracoden aus dem Expansusschiefer Norwegens. Norsk geol. tidsskr., Bd. 19.

Willi a m s A. 1962. The Barr and Lower Ardmillan Series (Caradoc) of the Girvan District, South-west Ayrshire, with descriptions of the Brachiopoda. Mem. Geol. Soc. London, vol. 3.

Will i a ms A. 1963. The Caradocian Brachiopod Faunas of the Bala District, Merionethshire. Bull. Brit. Mus. (Nat. Hist.) Geol., vol. 8, No. 7.

$\begin{array}{cc}\text { Институт геологии } & \text { Поступнла в редакцию } \\ \text { Академии наук Эстонской ССР } & 31 / \mathrm{V}{ }_{1968}\end{array}$

\section{HINTS}

\section{CREMNORTHIS JA PAURORTHIS (BRACHIOPODA) EESTI KESKORDOVIITSIUMIST}

Artiklis on kirjeldatud Cremnorthis uhakuana sp. n. uhaku, kukruse ja idavere lademest ning Paurorthis savalaensis sp. n. kukruse lademest. Nimetatud perekondade esmasleiud Eesti keskordoviitsiumist pakuvad huvi nii kohaliku stratigraafia kui ka nende üldise stratigraafilise ja geograafilise leviku seisukohast.

\section{HINTS}

\section{CREMNORTHIS AND PAURORTHIS (BRACHIOPODA) IN THE MIDDLE ORDOVICIAN OF ESTONIA}

The author presents a description of 2 new species: Cremnorthis uhakuana from the Uhaku, Kukruse and Idavere Stages, and Paurorthis savalaensis from the Kukruse Stage. The first finds of these genera in the Middle Ordovician of the East Baltic Area are ot interest from the standpoint of local stratigraphy as well as from the standpoint of the general stratigraphic and geographic distribution of these brachiopods.

\section{FAMILY CREMNORTHIDAE WILLIAMS, 1963}

Genus Cremnorthis Williams, 1963

\section{Cremnorthis uhakuana sp. n.}

$\mathrm{Holoty}$ e. Complete shell $\mathrm{Br} 4114$, Uhaku Stage $\left(\mathrm{C}_{\mathrm{I}} \mathrm{c}\right)$, Körgekallas, North-East Estonia. Pl. I, Figs $1-5$.

D i a g nos is. Cremnorthis of small size, triangular or trapezoidal in outline. Radial ornamentation consisting up to 45 costae and costellae, with modal count of $6-8$ per mm, anterior of dorsal umbo.

\section{FAMILY PAURORTHIDAE OPIK, 1933}

Genus Paurorthis Schuchert \& Cooper, 1931

Paurorthis savalaensis sp. $\mathrm{n}$.

Holotype. Brachial valve $\mathrm{Br} 4122$, Kukruse Stage $\left(\mathrm{C}_{\mathrm{II}}\right)$, Savala boring, depth 25.6-25.8 m, North-East Estonia. Pl. II, Figs 1-5.

Diagnosis. Shell of about medium size for the genus. Brachial interior with wedge-like cardinal process and large cordate adductor scars. Radial ornamentation consisting of fine costellae varying from 4 to 5 per $\mathrm{mm}$, at the antero-median margin. 